\title{
Pre-Service Teachers' Views of the Child-Reproducing or Challenging Gender Stereotypes in Science in Preschool
}

\author{
Annica Gullberg ${ }^{1} \cdot$ Kristina Andersson $^{1}$. \\ Anna Danielsson ${ }^{2} \cdot$ Kathryn Scantlebury $^{3}$. \\ Anita Hussénius ${ }^{1}$
}

Published online: 26 May 2017

(C) The Author(s) 2017. This article is published with open access at Springerlink.com

\begin{abstract}
We report how 47 pre-service teachers during their preschool placement in Sweden identify events related to gender and emerging science. We analysed their reflections on the situations with Gee's Discourse analysis. Two dominant discourse models were identified: the Discourse Construare, where pre-service teachers assumed that children have potential interests in a variety of subjects, and the Discourse Essentia, where children were regarded to have a stable core identity. In the latter discourse, the pre-service teachers' task would be to encourage the children to be who they are. The analysis found a connection between preservice teachers' views of the child and whether gender stereotypes were reproduced or counteracted. The Discourse Essentia is in conflict with the goal in the Swedish national curriculum that all children should learn science. We discuss how the different discourses affect whether children are stimulated or inhibited in their emerging science activities and interests. Based on the results from an analysis of answers reflecting the Discourse Construare, we have designed a model illustrating a process for gender-aware teaching.
\end{abstract}

Annica Gullberg

annica.gullberg@gender.uu.se

Kristina Andersson

kristina.andersson@gender.uu.se

Anna Danielsson

anna.danielsson@edu.uu.se

Kathryn Scantlebury

kscantle@udel.edu

Anita Hussénius

anita.hussenius@gender.uu.se

1 Centre for Gender Research, Uppsala University, Box 527, SE-751 20 Uppsala, Sweden

2 Department of Education, Uppsala University, Box 2136, SE-750 02 Uppsala, Sweden

3 Department of Chemistry and Biochemistry, University of Delaware, Newark, DE 19716, USA 
Keywords Gender - Gender stereotyping · Pre-service teachers · Science education · Teacher education $\cdot$ Views of children

\section{Introduction}

Sweden is generally regarded as one of the world's most gender-equitable countries, and since the 1970s, there has been an explicit political aim to promote economic equality between women and men (Weiner and Berge 2001). Despite the support for gender equality through government policies and programs, Sweden has a strongly gender-segregated labour market, and students' education choices also reflect this segregation. Assuming it is possible to influence students' choices, teachers are important agents in combating gender-stereotyped ways of thinking and gender-related stereotyped education choices. Students may establish their educational and vocational choices during childhood: therefore, it is important for girls and boys to have an unlimited range of possibilities and equal opportunities to develop and explore their abilities and interests. However, technology and physics are topics where stereotypical ideas are common. A boy with an interest in mechanics adheres to cultural norms, while a girl with the same interest may receive comments that allude to the field being unusual for females. In the realm of science, in order for all students to have equal access to technology and physics, we suggest that science teachers are required to have an understanding of how gender operates in society's different structural levels. Nevertheless, discussions regarding gender as macro- and micro-structures are rarely included in teacher education for science. This is problematic because the Swedish curriculum strongly emphasizes that teachers ensure adherence to gender stereotypes should not restrict girls' and boys' potential interests, choices and behaviours.

Previous research has examined preschool teachers' understanding of science attitudes towards science and gender, but there are few studies engaging preschool teachers to critically examine the role of gender in education, and how gender influences science teaching and learning. In our research project, we investigated how an integration of gender knowledge into science courses in preschool teacher education provided pre-service teachers with tools to examine gender norms in science and science teaching (Hussénius et al. 2014, 2015). The content of science courses was expanded and supplemented by introducing Harding's (1986) and Hirdman's (1990) theories of gender order to examine power constructs at different levels in society and to problematize the view that science produces objective knowledge. The discussion in this article focuses on an assignment pre-service preschool teachers completed during the field experience portion of the science courses within their teacher education. We analysed how the pre-service teachers used their knowledge of gender theories when discussing and reflecting on teaching practises in preschool. Our goal was to investigate preservice teachers' assumptions about children's abilities to learn in science and how those views might influence teaching and learning.

\section{Background}

In this background, we provide an overview of the relevant international and Swedish research for the study, including the theoretical frameworks used. The background is divided in four sections where the first one describes gender bias in Swedish education and academia. The 
second section provides two alternative explanations for gender differences. The third section enlightens how preschool teachers' underlying beliefs about subject, gender and the child might affect teaching. The final section describes edu-care and how science can be taught in preschool.

\section{Gender Bias in Swedish Education and Academia}

With an index of $0.8165,{ }^{1}$ Sweden is ranked fourth in the 2013 Global gender gap index (Hausmann et al. 2013). However, Swedish high school girls and boys express different subject interests in their choices of upper secondary school programmes (Sverige Statistiska centralbyrån 2012, data from 2012 are shown in Table 1). Only one of the 19 specified programme categories, the Science programme, ${ }^{2}$ showed no significant difference in student enrolment by gender $(P=0.0553)$. Technical programmes are almost exclusively chosen by boys, while nursing and child care programmes are chosen by girls (Table 1). This gender bias is more pronounced in higher levels of education in science and engineering. Of the students who commenced their $\mathrm{PhD}$ studies in the natural sciences during 2011, 39.5\% were female and $60.5 \%$ male, and in engineering, $28.8 \%$ were female and $71.2 \%$ male. This gendered pattern continues in the professional years, with only $17 \%$ of natural science and $11 \%$ of technology professors female. Although Sweden is one of the world's most gender-equitable countries, gender impacts people's educational and vocational preferences.

\section{Explanations for Gender Differences}

In a democratic society, individuals have the right to choose their areas of educational interests independent of gender. Swedish laws and governmental regulations explicitly and implicitly support this goal. The participation of girls and boys in science and technology programmes at the high school and the tertiary level clearly show that these are not independent choices: gender is an important controlling factor. There are two intrinsically different ways to explain and answer the question as to why students' interests and choices are so intimately connected with gender. One explanation is that there are genetic predispositions for certain disciplinary domains, and sex is an example of a genetic predisposition. Another explanation is that sociocultural factors convey different views connected to gender and thereby influence students' choices. Extensive studies have been carried out in order to find genetic/biological explanations for humans' different achievements in different subject areas but have so far not revealed any correlation with gender alone (e.g. Moss-Racusin et al. 2012). This research examines differences between the sexes, for example, that boys/men are mathematically more talented than girls/women are, and claims biological explanations rather than cultural for those differences. A commonly used explanatory model originates from a nineteenth-century theory by the British sex researcher Ellis, which says that a population's mathematical talent follows a normal distribution with the same average for women as for men but with a more flat curve for men (Shields 1975). Consequently, more men were among the most and the least talented. However, some years ago, researchers analysed mathematics test scores of school children in

\footnotetext{
${ }_{1}^{1} 1.0$ represents an equitable society.

2 The Science programme is the broadest programme when considering the number of different subjects covered. It also recruits students with other interests than science since it is the only high school programme in Sweden that offers all the pre-requisites students need to apply for all undergraduate degree.
} 
Table 1 Results for pairwise comparison (Chi-squared test) of females and males graduated from programs in upper secondary school in 2010/11 in Sweden

\begin{tabular}{|c|c|c|c|c|}
\hline \multirow[t]{2}{*}{ Program } & \multicolumn{2}{|c|}{ Numbers $^{\mathrm{a}}(\%)^{\mathrm{b}}$} & \multirow[t]{2}{*}{ Chi-squared ${ }^{b}$} & \multirow[t]{2}{*}{ P-value ${ }^{b}$} \\
\hline & Females & Males & & \\
\hline Handicrafts & $2772(90)$ & 291(10) & 2010 & 0,0000 \\
\hline Restaurant management and food & $359(80)$ & $89(20)$ & 163 & $<0,0001$ \\
\hline Health and social care & $2909(80)$ & $749(20)$ & 1280 & $<0,0001$ \\
\hline Child and recreation & $2613(76)$ & $810(24)$ & 950 & $<0,0001$ \\
\hline Arts & $4128(69)$ & $1866(31)$ & 854 & $<0,0001$ \\
\hline Natural resource uses & $2060(68)$ & $957(32)$ & 403 & $<0,0001$ \\
\hline Business and administration & $3049(68)$ & $1431(32)$ & 584 & $<0,0001$ \\
\hline Int. Baccalaureate and Waldorf schools & $427(66)$ & $220(34)$ & 66 & $<0,0001$ \\
\hline Hotel and tourism & $2146(64)$ & $1220(36)$ & 255 & $<0,0001$ \\
\hline Media & $2664(63)$ & $1598(37)$ & 267 & $<0,0001$ \\
\hline Social science & $16,375(62)$ & $9890(38)$ & 1601 & 0,0000 \\
\hline Science program & $6720(49)$ & $6944(51)$ & 3,67 & $0,0553^{\mathrm{c}}$ \\
\hline Other & $1050(45)$ & $1300(55)$ & 27 & $<0,0001$ \\
\hline Technology & $1229(21)$ & $4648(79)$ & 1989 & 0,0000 \\
\hline Industrial technology & $340(13)$ & $2283(87)$ & 1440 & $<0,0001$ \\
\hline Building and construction & $499(10)$ & $4556(90)$ & 3256 & 0,0000 \\
\hline Vehicle and transport & $374(9)$ & $3603(91)$ & 2622 & 0,0000 \\
\hline Electricity & $279(4)$ & $5932(96)$ & 5145 & 0,0000 \\
\hline Energy & $43(4)$ & $1110(96)$ & 987 & $<0,0001$ \\
\hline Total & $50,036(50)$ & $49,497(50)$ & 2010 & 0,0000 \\
\hline
\end{tabular}

${ }^{\mathrm{a}}$ Numbers from Sverige Statistiska centralbyrån 2012

${ }^{\mathrm{b}}$ Percentages (in parentheses), chi-squared and $P$ values calculated by the authors

${ }^{\mathrm{c}}$ Non-significant $P$ value

41 different countries in the Programme for International Student Assessment (PISA) project, and the results dispelled Ellis's hypothesis. In several countries, including Denmark, the Netherlands and Switzerland, equal variation among girls and boys was shown, with as many girls as boys among the most talented students (Hyde and Mertz 2009). The researchers concluded that the lack of a universal sex pattern ruled out biological explanations. Thus, social and cultural influences may explain whether women choose to study mathematics or not (Hyde and Mertz 2009). Furthermore, Spelke's (2005) comprehensive review reported that women and men share a set of biologically based cognitive abilities that contribute to mathematical and scientific reasoning, and thus both women and men have the potential to develop their talents for mathematics and science (Spelke 2005). However, as mathematics and science in society are stereotyped as masculine, feelings of inferiority among women may affect their performances in these subjects. This effect, called stereotypical threat (Spencer et al. 1999), explains the gap favouring men at the higher end of academic achievement (Lindberg et al. 2010; Stoet and Geary 2012).

Recent studies problematize views such as seeing talents for a subject as inherent abilities. Claxton and Meadows (2009) studied high-performing students with a talent for a specific subject and argued for a reconsideration of intelligence as an innate cognitive capacity. Rather, these researchers argue that people possess non-cognitive skills such as attitude, motivation and perseverance that characterize high-performing students (Claxton and Meadows 2009). These are learned skills, and students who are seen as talented already have acquired the skills in different social contexts. Adults' guidance, support and interpretations of a child's activities 
can affect the child's development of social, perceptive, cognitive and language skills, which can shape the child's behaviour. It is important for children who have not had the opportunity to develop these skills before they start school to gain these skills through additional guidance and support in pre- and primary school, argue Claxton and Meadows (2009).

In a study that highlights the underrepresentation of women in science within mathintensive fields, Ceci et al. (2009) analysed competing claims of biological and sociocultural causation. Their analysis provides evidence that socio-cultural constraints represent the most powerful explanatory factor for performance differences between sexes. In summary, research does not support genetic differences between girls and boys as an explanation for the skew in choices of education and/or areas of interest. Rather, bias in gender is an effect of culturally stipulated contexts and thus possible to counteract. This is also the standpoint of this article's authors.

\section{Teachers' Understandings of Science, Students and Gender}

From birth through adolescence, socio-cultural factors influence us in unconscious ways and thereby affect our views of who is potentially suitable for specific knowledge and skill areas and who is not. Teachers' beliefs about a subject and about a child's inclinations to develop knowledge in that subject area have an impact on whether the child's learning will be stimulated, challenged or inhibited (Andersson 2012). Further, Johansson (2011) argued that the basic assumptions we make about an individual, often unconsciously, will also affect our interactions with that person. According to Hundeide (2006), our views of a child's personality, and thereby our treatment of the child, is based on our past experiences and on societal norms regarding gender, class, ethnicity and age. Teachers' understandings of a child will in turn affect the child's learning. Research has also shown that teachers' presumptions and expectations of a child are important for the children's performances in science subjects (Huang and Fraser 2009; Kahle and Meece 1994; She and Fisher 2002). Although teachers, when questioned, say that they have the same expectations for girls' and boys' achievements in science, their teaching practises do suggest the opposite (Kahle et al. 1991; Kahle and Meece 1994).

The culture that shapes children's interests begins early and depends on how the adults present and engage the children with the subject. Previous studies have shown that teachers with negative experiences of science and technology avoid teaching those topics (Appleton 2005), and when they are forced to teach such topics, their negative experience or low selfconfidence affects their students' learning. For example, girls' performances in mathematics declined when taught by female teachers with low math self-confidence, while the boys' performances were unaffected (Beilock et al. 2010). Moreover, teachers' conscious or unconscious beliefs about the subject, gender and children influence their pedagogical practises. Although the teachers' views on science and students' abilities are clearly gender-related, discussing assumptions about the influence of gender is rarely seen as an important facet of a teacher's pedagogical knowledge (Hussénius et al. 2013; Scantlebury 2014).

\section{Edu-Care and Science in Swedish Preschools}

In Sweden, preschool is well established, and preschool placements are offered to all children, 1 year old and up. Eighty-three percent of children aged 1 to 5 years and $95 \%$ of children between 3 and 5 years attend preschool (Swedish Schools Inspectorate 2012). Ninety-eight 
percent of preschool teachers and childcare assistants are women and almost 50\% have a degree in early childhood education (Edström 2009).

Preschool's mandate has expanded from providing children with social care to overseeing their development and learning with an emphasis on the competent child. Swedish preschool is described internationally as 'edu-care' (Swedish Schools Inspectorate 2012), a combination of education and care. In the national curriculum framework, influenced by post-modern global discourses, the individual child is viewed as a competent co-actor (Edström 2009). The child is considered autonomous, competent, active and as a creator of her/his own knowledge, identity and culture (Corsaro 2005; Dahlberg et al. 2002; Halldén 2007; James et al. 1998). Thus, children are placed on the same level with adults, with rights and abilities to act rationally and logically and with abilities to influence their environments. This image of children as competent co-actors has led to a learning objective of acknowledging and developing the individual child's identity. For example, this goal is stated as "preschool should strive to ensure that each child develops her/his identity and feels secure in it" (Lpfö98 revised 2010 p. 9). Over the last decade, the view of children as competent co-actors has had a normative impact on teachers' attitudes and activities and is also the prevailing idea in preschool teacher education (Brembeck et al. 2004).

Since 1998, the national curriculum has stated that the preschool "should be characterized by a pedagogical approach, where care, socialisation and learning together form a coherent whole" (Lpfö 98 revised 2010 p. 9). The revision of the curriculum enhances the goals and learning objectives for three subject areas: spoken language and communication, mathematical development and science and technology development. Regarding science, the underlying argument proposed by the government document is that young children who experience science activities will develop and deepen their interest in science. Such early exposure may lead to a career trajectory in science (Sjøberg 2000). Like Sweden, other countries have noted the importance of teaching and learning science in early childhood, and this new emphasis on science in the early years of schooling has initiated a discussion among researchers about what science means in preschool (Andersson and Gullberg 2014; Eshach 2006; Siraj-Blatchford 2001). An example of wording in the revised curriculum (Lpfö 98 revised 2010 p. 11) is that "The preschool teacher is responsible for carrying out activities with the children so their interests in science and technology are stimulated and challenged." The Swedish curriculum also states that children shall develop an interest in different subjects where play is an integrated part of learning. As a consequence, science in preschool is inseparable from play, and different play activities are viewed as emerging science (Siraj-Blatchford 2001). Building with blocks, splashing with water, baking buns and sliding down inclines are moments of scientific experiences. All activities that involve interactions with physical phenomena can be seen as precursors for developing scientific understandings. Siry (2013) stressed the teachers' responsibilities to value and make use of children's unprecedented knowledge about science phenomena. Hence, the focus in preschool is not on correct understandings of scientific phenomena nor to learn scientifically correct concepts but rather to include science into the preschool agenda. Thulin (2011) placed an emphasis on teaching children the nature of science by stating that emergent science is about establishing children's interests for problem solving and investigations with natural phenomena as learning objects. In doing so, students would develop positive attitudes towards science and technology. In a previous paper, we used two different epistemological perspectives to discuss the competences preschool teachers needed to successfully teach science (Andersson and Gullberg 2014). One important aspect was teachers' abilities to empower children in science activities, and another aspect was what is 
acknowledged as science in preschool. In this paper, we will use a broad meaning of the concept of science, science teaching and learning as culture (Siry 2014). This broad understanding of science is sometimes referred to as emerging science (Siraj-Blatchford 2001; Siry 2013) or small science (Sikder and Fleer 2015) and incorporates play.

Furthermore, Sweden is maybe the only country that explicitly states in its curriculum documents that preschool teachers shall counteract traditional gender patterns:

Preschool should counteract traditional gender patterns and gender roles. In preschool, girls and boys should have the same opportunities to develop and explore their abilities and interests without restrictions based on gender stereotypes. (Lpfö 98 revised 2010 p. 5) Preschool teachers will work to ensure that girls and boys have equal influence on activities and equal access to facilities. (Lpfö 98 revised 2010 p. 12)

The strong wording and clear objective formulations place heavy demands on preschool teachers' gender knowledge and awareness and their abilities to challenge children's stereotyped attitudes and practises.

\section{Aim and Research Questions}

Shulman (1986) included gender as a part of a teacher's knowledge base for teaching and learning. Taking that focus into account as well as the desire to diminish the gender bias in students' educational interests, we integrated gender theories into the science and technology courses for pre-service teachers. The gender aspects were tightly linked on a very topical level and not just treated as general understandings. During their preschool field placements, the students completed an observation assignment that directed them, by using gender theoretical frameworks, to identify, describe and analyse preschool teaching and/or learning situations where gender mattered. Guided by the following research questions, the study explored how pre-service teachers, during their preschool placements, understood and interpreted gendered situations in the context of science and technology:

- How do pre-service preschool teachers argue when presenting gendered situations?

- In what ways do their arguments reveal insights about their views of children regarding children's gender and science interests?

- What discourses concerning children, science and gender are represented in the empirical material?

\section{Theoretical Framework}

The point of departure in this research project is to problematize the idea of science as objective and value-neutral in accordance with feminist critique (Haraway 1991; Harding 1986; Keller and Longino 1996). We used gender theories to both understand and problematize the culture of science and its reproduction because these theories provide the tools for examining and understanding how the interaction between gender and power impact girls and women. In science education research, gender is often seen as an individual trait (Hussénius et al. 2013). In order to challenge and change gender stereotypic norms, it is important to examine gender, not only as an individual trait but also as thought, organizational 
and cultural structures that impact human lives. Therefore, to include all relevant aspects of gender, we use Hirdman, Harding and Rubin's theories of gender order, where gender is understood as socially, culturally and biologically constructed and constituted on different levels: the symbolic, the structural and the individual (Harding 1986; Hirdman 1990; Rubin 1975). The symbolic level of gender is the archetypical idea of woman and man from different cultures as it is expressed in language, for example, by retaining dichotomies where the oppositional pairs are assigned feminine and masculine meanings, such as emotion-rationality, subjectivity-objectivity and nature-culture (Harding 1986). These symbolic meanings of gender generate understandings of feminine and masculine and extend into appropriate practises for women and men, that is, how they should act, dress and engage in different contexts. At the symbolic level, the natural sciences, technology and mathematics are regarded as high-status subjects and are viewed as masculine. The structural level is how society is organized regarding gender, e.g. the divisions of labour. In most cultures, women and men have different tasks and roles. Women in one culture may have the same tasks as men in another culture, but within the same culture, labour is often divided by gender. What is consistent across cultures is that a higher status is attributed to men's labour when compared to women's.

The individual level is individuals' socialization into a gender identity where the structural and the symbolic levels have great impacts on this process. But, this process can also be dialectic, and individual gender can impact and transform the structural and symbolic gender. A lack of awareness about one's own actions can be understood using Butler's concept performativity (Butler 1990). Butler argues that gender is constituted through repeated acts; through gestures, play, clothes and speech, gender is formed over and over again. The repetition goes beyond the individual her/himself by its power in history, which is constantly reproduced in time and space. These repeated acts are embedded in the body and thus become parts of one's identity. For an individual, this is taken for granted as a natural state and is thus expressed as a form of gender blindness. Similarly, teachers can carry assumptions concerning a subject's natural tendencies. The symbolic values attributed to different science subjects produce different statuses, thus contributing to a hierarchical order, and gender is an integral part of this power hierarchy. The more a subject is associated with rationality, logic, objectivity and pure thinking, the higher its status and the more it is perceived as masculine (Harding 1986). The consequence of this line of thought is that children are consciously or unconsciously sorted as predestined for different subjects according to gender.

\section{Methods}

To provide an overview of the methodology used in the present study, this section has been divided into three separate parts, each one with its own sub-heading; data collection for the study, ethics, and analysis of the empirical data.

\section{Data Collection}

The Swedish preschool education includes seven semesters (3.5 years). During these semesters, pre-service teachers have in total 20 weeks of preschool placements that are integrated throughout the program, varying from 2 to 6 weeks. The present study was conducted at a Swedish higher education institution, with participation of 47 pre-service preschool teachers 
during the first 2 semesters when the students studied science (Hussénius et al. 2014, 2015). A majority of the preschool pre-service teachers are female, which reflects Swedish employment patterns in preschools (Edström 2009). All of them were born in Sweden and a majority grew up in small towns and rural settings. Many had prior work experience (from 1 to 20 years) before enrolling in the programme and about a fifth were substitute teachers in preschool or primary schools.

Gender theory sessions were integrated within the science courses. An important element was the use of cases (descriptions of real classroom situations which involved learning science) as prompts for students' reflections, group discussions and gender-theoretical perspective analyses (Andersson et al. 2009). A detailed description of the gender theory sessions is provided in Hussénius et al. (2015).

At the end of the science courses, students were given assignments to conduct during a 6-weeklong preschool placement period. During placements, students always get assignments to carry through. These assignments are anchored in the university course and are followed up at university after the placement. The particular assignment in this study required the pre-service teachers to identify important examples of children's emerging science learning they experienced. The preservice teachers identified and reflected upon science/technology activities where gender was of significance (Appendix) such as during interactions between child(ren) and child(ren), child(ren) and adult(s) or child(ren) and material(s). The investigations were summarized in written reports and their observations were also discussed at seminars. The empirical material used in the present article consists of these reports (1-2 pages) from the 47 preschool student teachers and field notes from follow-up seminars where the students were devided into five groups.

\section{Ethics}

Although the assessments within the science course were compulsory, the participation in the research study was voluntary. The pre-service teachers were informed about the study and those who wanted to participate (47 of 53) signed a written consent form. The coordinators of the teacher education programme at the higher education institution were informed and gave their approval for the project, which includes access to assignments that students perform during preschool placement. All the assignments in preschools are presented to parents in preschools by ordinary praxis in the teacher education programme, and the parents have possibility to deny participation for their children. When the pre-service teachers are asked to describe interactions where gender was of significance, they were told to exchange names and other things that could reveal persons identities. It is also important to notice that the study objects are the pre-service teachers, not the children, parents or preschool teachers. The assignment in preschool was just used as a method to reveal the pre-service teachers' views. In addition, other teacher educators within the science course where the research took place approved the project and had access to the educational instructions about gender that we used in the course. The pre-service teachers' written assignments and the recorded seminars were anonymized and only available for the researchers in the project. Names and identifying factors in the data were anonymized as well as the preschools (including the preschool teachers and other persons at the preschool) where the pre-service teachers were placed.

\section{Analysis}

The analysis is described in two parts: first, Gee's theoretical discourse models and second, how the analysis was performed in practice. 


\section{Gee's Discourse Models}

In order to analyse the pre-service teachers' views about children, gender and the children's abilities to develop an interest in science, we used Gee's discourse analysis (Gee 2005). Gee's discourse concepts include a broad socio-cultural context in which language is used. Gee posits that our world is built and rebuilt through the use of language together with "actions, interactions, non-linguistic symbol systems, objects, tools, technologies and distinctive ways of thinking, valuing, feeling and believing" (Gee 2005, p. 10). Discourse models are described by Gee as theories (storylines, images, explanatory frameworks) that people hold, often unconsciously, and use to make sense of the world and their experiences in it (Gee 2005, p.61). A discourse model is and must be a simplification of a reality and can thereby help us to understand complex contexts by highlighting central phenomena and ignoring details. Discourse models will therefore show what is assumed appropriate, typical, or normal but also tell us about what is not considered selfevident. In our analyses of the data, we have been driven by the following variations of Gee's questions in order to connect to the discourse models:

- What discourse models are relevant here? What must I, as an analyst, assume that people feel, value and believe, consciously or not, in order to talk (write), act and/or interact this way?

- What sorts of discourse models, if any, are being used here to make value judgments about oneself or others?

- How consistent are the relevant discourse models here? Are there competing or conflicting discourse models at play? (Gee 2005, p.92-93)

\section{Analysis in Practice}

In order to sort the data (the pre-service teachers' texts and field notes from seminars), thematic analysis was used (Braun and Clarke 2006). The pre-service teachers' texts consisted of two parts, the descriptions of situations during their preschool placement when they perceived that gender influenced children's teaching and/or learning and the reflections on these situations. To organize the data, we used QSR NVivo 9, software for qualitative analysis. This was an iterative process where different themes were identified and reformulated as the analysis moved forward.

In the first round of coding, we organized categories according to how preschool preservice teachers characterized the gendered nature of the situations (Table 2); whom did the pre-service teachers observe (e.g. children, parents), where took it place (e.g. the hall, the doll corner), what was happening (e.g. children crossing gender norm boundaries, teachers' gendered interactions with parents).

Here follows examples from two of the categories in order to show how we have classified the pre-service teachers' texts about the situations. First, the category "Children crossing gender boundaries":

A two and a half year old boy walks around with a doll in a doll's pram. He sits down next to another boy who is drawing a picture. He says, "I'm the mum and you're the dad". He sits there for quite a long time. The other boy is busy drawing but is still taking part in the play. 
Table 2 Sorting and categorizing situations reported by the preschool pre-service teachers

\begin{tabular}{|c|c|c|}
\hline Object of interest & & Category \\
\hline \multirow[t]{9}{*}{ Children } & Where (place)? & The hall \\
\hline & & The doll corner/apartment \\
\hline & & $\begin{array}{l}\text { Children activities led by a preschool teacher } \\
\text { (so called gathering) }\end{array}$ \\
\hline & What is about (topic)? & Colour (blue or pink) \\
\hline & & Material \\
\hline & & Language and addressing each other \\
\hline & What happens? & $\begin{array}{l}\text { Girls and boys do different things because } \\
\text { they are different }\end{array}$ \\
\hline & & Children adhering to gender norms \\
\hline & & Children crossing gender norm boundaries \\
\hline \multirow[t]{2}{*}{ Preschool teacher } & & Teachers reinforce gender stereotypes \\
\hline & & Teachers challenge gender norms \\
\hline \multirow[t]{3}{*}{ Parents } & & Parents' stereotypical behaviour \\
\hline & & Parents' challenge gender norms \\
\hline & & Different gender norms in different cultures \\
\hline Remaining & & Unclear gender situation \\
\hline
\end{tabular}

The second example shows the category "Parents' stereotypical behaviour":

One afternoon, I was sitting with a few children building with Lego when one of the children's mothers arrived to pick up her daughter. She really did not like her daughter to play with Lego because it is a "boy's game" as she put it. If this is what this girl hears from her mother, she will probably not want to play with Lego anymore. After all, she is a girl. Not to mention, this girl ALWAYS arrives at preschool dressed in a pink dress and tights. The girl also has a pair of heals as indoor shoes while the other children have slippers or no shoes at all. I believe the parents rule their children and what you do as a preschool teacher doesn't make any big difference. The children still listen to and do as their parents. Well, I think this is an extreme situation but this kind of situation is probably not that usual.

In the second step, the students' reflections of their experienced situations were coded and categorized (Table 3). The themes were, for example, "Gender as two static dichotomies" and "Socio-cultural impact on children as an explanation of gender norms". Within the themes, a number of sub-themes evolved. Furthermore, we analysed how different themes correlated with each other.

After this organization of the collected data, we used Gee's discourse analysis (2005) together with gender theories (Harding 1986; Hirdman 1990; Rubin 1975) in order to investigate what discourse models prevailed among the pre-service preschool teachers' texts. By applying Gee's analytical questions to the pre-service teachers' texts, the discourse models emerged: For example, what explicit or tacit norms could be detected, what kinds of values were competing, and which might be linked together.

\section{Results}

Three main discourses emerged from the analyses of the pre-service preschool teachers' descriptions and reflections of situations in preschool where they thought gender mattered 
Table 3 Categories of the pre-service teachers' analysis of situations connected to gender issues

\begin{tabular}{ll}
\hline Category & Sub-category \\
\hline Gender as two static dichotomies & Biological differences exist between girls and boys \\
& Both females and males are needed as role models \\
& Preschool teachers have stereotypical gender views \\
& Preschool teachers interactions with children \\
Socio-cultural impact on children as & and parents \\
an explanation of gender norms & Parents influence the children \\
& Challenge gender norms \\
& Gender does not matter \\
Significance of children's gender & Gender should not matter (but does) \\
& Overcompensation of girls \\
Pre-service teachers' self reflection & Is or has become gender aware \\
& Scrutinize their own behaviour \\
& Want to challenge and change the prevalent \\
& gender order \\
Using theoretical frameworks & Pre-service teachers analyse their situations \\
& with gender theories
\end{tabular}

(Fig. 1). Dependent on foci, the discourses were labelled as Construere, Essentia and Ambivalent. Using the data from the 47 pre-service teachers, the discourse Construere formed the largest group followed by Essentia. Three of 47 of the pre-service teachers expressed statements that were classified both as Construere and as Essentia. In order to visualize this set of answers as well, a discourse called Ambivalent was formed. Five of the participants did not write any descriptions or judgments regarding children's interests, therefore not allowing us to categorize their statements, hence labelled as uncategorizable (Fig. 1).

The discourse Construere is characterized by viewing the children as versatile, with potential interests in a variety of subject matter topics. According to this discourse, teachers have agency to offer and stimulate children in the direction of different kinds of activities, thereby opening up possible new interests. Within Construere, three awareness-oriented insights could be recognized, all of which can operate at the same time and co-interact with each other. First, pre-service teachers were able to detect situations in preschools where they thought children were treated differently according to their sex. Second, some of them described situations where they, or a preschool teacher, counteracted to prevent traditional and stereotypical gender patterns. In the third awareness-oriented insight, the pre-service teachers showed how they were able to reflect upon their own stereotyping behaviours or thoughts. Within the other view of children, Essentia, the pre-service teachers argued that children have a stable core identity and need to be who they are. In this discourse, we often found statements labelled as reproducing stereotypes and quotations showed that stereotypical gender behaviours within science activities were seen as natural.

The discourse Ambivalent contains reflections where the same person articulates both Construere and Essentia. These statements could be defined as either of these discourses: however, a singular categorization would overlook an important characteristic. These texts showed ambivalence or uncertainty. Instead of describing and reflecting over the situations, the particular students posed many questions. The discourse Ambivalent illuminates the ongoing internal processes of negotiation between the two dominant discourses. In the following section, illustrative examples verify the discourses and also shed light on how we have performed the analysis. In the last part of this article, implications of these discourses will be discussed. 
Fig. 1 Shows the proportion of students within the three discourses Construere, Essentia and Ambivalent. Five students' data could not be classified and are shown as 'uncategorizable'
Construere Essentia Ambivalent Uncategorizable

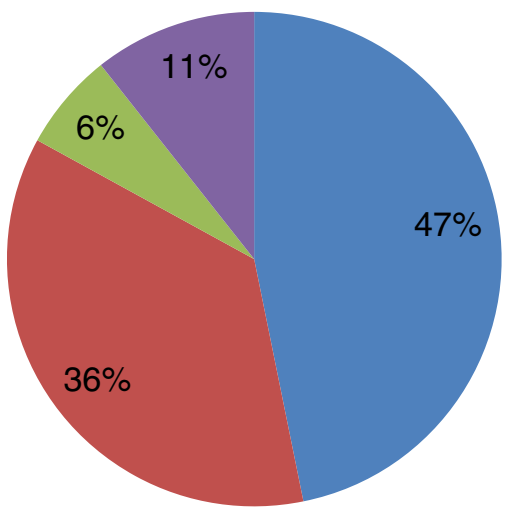

\section{The Discourse Construere}

The pre-service teachers who in their written assignments expressed statements categorized as the discourse Construere considered teachers to have an important role in facilitating and presenting new topics for children. These student teachers articulated the teachers' responsibilities to encourage children to broaden their interests. They stress the importance of challenging children to engage in activities they are not used to because of traditional gender stereotypical viewpoints. Below, we present the three subcategories within the discourse Construere. Pre-service preschool teachers; (1) detect gender stereotyping, (2) counteract gender stereotyping, and (3) reflect upon their own gender stereotyping.

\section{Pre-Service Teachers Detect Gender Stereotyping}

In the empirical material, there are pre-service teachers who selected situations that directly related to activities where the preschool teacher interacted with children in a way that showed that she/he had a pre-conceived idea. In the excerpt below, a pre-service teacher, Maja, describes a situation where the children were playing through building and construction with Duplo Legos, an activity in preschool that can be regarded as indicating a potential early stage of interest in technology:

They had received a new Duplo kit in the form of a police station in the 'young-children part' of the preschool. Five two-year-old children, four boys and a girl, sit around a table together with a teacher. She lets the children explore the Duplos which includes motorcycles, a helicopter, cars, figures, a small bag, a chair and pre-made walls to build a police station. The children rotate around the table, test and investigate the toys.... After a while, the girl comes to one of the houses and tries to put a motorcycle into the house. One of the boys plays with the other house which has cars and blocks inside. The teacher talks to the boy and points out that he has a nice garage for his cars. On the other hand, she hands over a small chair to the girl and wonders if she wants it for her characters to have something to sit on in her house. (Maja)

Later on in the text, Maja reflects upon this situation in the following way: 
In this example, the teacher has the presumption that the girl is playing that the building actually is a home for her characters. The preschool teacher ascribes to the girl something the preschool teacher actually does not know. That is because she has not tried to figure out what the girl really is playing. (She assumes) girls will be nurturing and her characters need something to sit on. The boy, however, she assumes is playing that the house is a garage where he has his cars. If the teacher had tried to understand what the girl and the boy were playing, her understanding might have been different. The Swedish Delegation for Equality in Preschool writes in their report that in the commercial toy supply, boys are expected to play with tools and vehicles, while girls are expected to play with things that are connected to caring and beauty. During this observation, the girl took as much initiative to explore the seemingly boyish material, but the educator reinterpreted the material for her. /.../ Hirdman (1990) states that in society, the male is the norm and at the same time the sexes are separated. She also points out what is feminine and masculine. ...To solve this, I think we who work in preschools need to have critical perspectives of societal norms and encourage things that break our preconceived norms. In my opinion, preschool should make use of queer [theory]. (Maja)

From the excerpt above, it is clear that Maja is able to recognize and detect gender stereotypical situations. We can see that Maja observed that the teacher treated the children differently depending on her assumptions about the children's interests and thus controlled the children's play. Maja's interpretation is that the children's play is gender neutral, but the preschool teacher engaged in the activities and gendered their play as she "reinterpreted the material for [the girl]". Maja shows that she realized possible consequences of a genderunaware teaching, that teachers' preconceptions about children and their interests are controlling for children's activity choices and for the direction a game takes. Maja argues that preschools "need to have critical perspectives on societal norms and encourage things that break our preconceived norms". These examples show that Maja views children as flexible and that the preschool should offer opportunities for all children to engage in a variety of different subjects and activities. In order to achieve this scenario and to challenge the preschool teachers' presumptions, she proposed knowledge about queer theoretical tools.

\section{Pre-Service Teachers Counteract Gender Stereotyping}

In the case above, Maja not only detected gender-stereotyping views, she also gave suggestions on how to counteract such views by using norm-critical perspectives. Another student, Anna, described a situation where preschool teachers guided children's activities into genderstereotypical patterns and then reflected on it:

The teachers planned to start a 'friendship group' in order to find a way towards better cooperation between three boys in the group of children. The boys often played together, but all of them wanted to be in charge and had a difficult time agreeing upon things. Since the boys shared a common interest in dinosaurs, the teachers proposed the idea that the boys should work together on constructing and playing with dinosaurs. In order to organize this, the project needed two more children. The teachers started to discuss different possible ways of putting the friendship group together, and all different suggestions consisted of just boys. I raised the question of why girls couldn't be included in the group. The teachers were completely taken aback and confessed that 
they hadn't even considered that. At the same time, they argued that all the suggested boys were very interested in dinosaurs and they wanted to bring these boys together with the other boys. The friendship group, which I persuaded them to call the dinosaur group, ended up consisting of five boys.

It's frightening that the teachers didn't even consider that girls could be part of the group. Surely, we should have the children's own interests as our points of departure in what we are doing, but there were several girls in the group who also were interested in construction and played with dinosaurs. My experience was that the teachers prioritized the idea that the boys found a way to collaborate and formed a group of friends. To encourage the children to play in other constellations wasn't anything that the teachers seemed to reflect upon. That the project was about science/technology possibly also contributed to the choice of children if they assumed boys are more interested. (Anna)

In Anna's reflection upon the teachers' actions, she interpreted that the teachers actively separated girls and boys, that the teachers' preconceived notions about the subject (science/ technology) was relevant to this separation, and she expressed that these actions depended on the teachers' lack of gender awareness. Thus, Anna highlighted that the formation of the friendship group was a result of the teachers' assumptions about the subjects. In other words, the goal for the pedagogy of science was pushed into the background by the preschool teachers' overarching goal of facilitating boys' cooperation. The girls' interests were sacrificed in favour of prioritizing the boys' needs.

Our interpretation of Anna's situation draws upon Harding's three levels of gender order: the preschool teachers were reproducing stereotypical gender structurally by dividing the children according to gender and imposing on them different subject interests. Since the project can be regarded as a science activity, there was an underlying assumption that boys have a greater interest than girls do. This kind of action by the preschool teachers is explained by feminist scholars as the expression of science as carrying a symbolic masculine gender (Haraway 1991; Harding 1986; Keller and Longino 1996).

In the example above, Anna not only detected and reflected on a gender-stereotyping situation; she asked critical questions to the preschool teachers and presented their stereotypical thinking. Anna experienced that knowledge about equality and gender was not taken into account. Our interpretation is that Anna felt secure enough in her own gender knowledge with confidence that she could question the experienced preschool teachers' suggestions. It is possible that the teachers' agendas in forming a friendship group resulted in a better social climate. However, the teachers ignored that the group formation could have consequences for other children, especially the girls, which Anna noted. Anna demonstrates that by identifying the separation of the sexes proposed by the preschool teachers and acting based on critical analysis, she opens up an opportunity for girls to gain access to science activities.

\section{Pre-Service Teachers Reflecting upon their Own Gender Stereotyping}

The above situations are examples of pre-service teachers identifying situations where gender matters and where in-service teachers act without demonstrating gender awareness. Another level of awareness is the ability to reflect upon one's own thoughts and ideas, as shown in the quote below. It describes a morning drop-off situation in the preschool hallway, witnessed by the pre-service teacher Stina: 
In the morning, two parents come and leave their child in the preschool. The teacher meets them and one girl is crying. The teacher asks if the girl doesn't want to play in the doll corner together with two other children who are playing there. The girl nods and wants to join the other children. Later the same morning, another mother comes and leaves her daughter. The mother points to the 'car carpet' and asks if the girl wants to play with cars and the girl nods.

This made me think about how the teachers differentiate between boys and girls when they help them to start playing. My interpretation is that in this situation patterns about what is male and female are highlighted when the teacher asked the girl if she wants to play in the doll corner. What I found interesting in this observation was that the other mother asked her daughter if she wanted to play on the car carpet. In this case, the teacher asks the girl if she wants to play with dolls, a typically 'girly' activity, whereas the mother maybe wants to act in a more gender-neutral way and wants to encourage her child to play with cars, which is more 'boyish'. From my experience of meeting with parents, this is an unusual behaviour for them as well as for preschool teachers. This made me ponder how important it is to stimulate and support children in engaging in a variety of activities, especially those they aren't used to. I was struck by this and had a lot of thoughts about how we often in preschool connect material and rooms to the stereotypical views of girls and boys. In retrospect, I also thought about why I reacted when the mother asked the girl if she wanted to play with cars. This made me realize that I also have preconceptions about typical toys for boys and for girls. (Stina)

Here, we can see how Stina detected a situation where children were directed to different activities, in one case depending on what is considered appropriate for girls and boys respectively and in the other case in contradiction to stereotypical gender patterns. This made her start to reflect on her own role as a preschool teacher and on the importance of guiding and encouraging children to activities they at first do not choose by themselves. In Stina's view, the children are not predetermined to certain abilities: instead, her view of children is in line with the discourse Construare. Stina observed that the preschool teacher guided the girl to a specific room and materials, and she problematized the idea that preschool teachers actually differentiated boys and girls. Moreover, Stina noted and was surprised by her own reaction when a mother led her daughter to the car carpet. That the girl was about to play with cars should not be anything noteworthy, but Stina experienced contradictory thoughts about the mother doing the unexpected. Her quote shows a process of selfreflection about how gender and subject matter interact.

\section{Discourse Essentia}

The second dominant discourse model that appeared in the empirical material, discourse Essentia, takes a point of departure from an assumption that children from birth have a stable core identity, and instead of influencing children, teachers should let them be who they are. Within this discourse model, pre-service teachers stressed that it is important to enhance the children's individuality and autonomy. Children that cross the borders of gender stereotypes should feel safe to do that, and characteristic expressions from the pre-service teachers are that the preschool environment should be tolerant or accept the border-crossing children. Several statements within this discourse used a biological explanation model for gender differences between the sexes. For example, the pre-service teacher Karin argues that the differences between girls' and boys' plays are innate: 
In the interactions between preschool teachers and children, I found that this preschool has worked with gender issues, and therefore, I think the teachers were very good at and aware of how they communicated with the children. One thing that I noticed was when the children had 'free play' activities; the boys chose Legos or cars while the girls wanted to paint and draw. I think that these behaviours are innate, because no adult made choices for the children or did anything to influence them. (Karin)

Without giving explicit examples, Karin argues that the preschool teachers at her preschool placement actively worked with gender issues, and therefore, they are not responsible for the separation of the sexes. Karin noticed a stereotypical gender pattern in children's free choices of play, where the children picked activities and stated that these choices took place without influence from the preschool teachers. Therefore, she concluded that these behaviours are innate. Karin overlooked the possibility that the children are exposed to other socio-cultural influences, both within and outside the preschool.

In the thematic analysis, we noted that pre-service teachers that expressed "biological explanations for gender differentiations" also expressed an essentialist view of children, as illustrated by the example below:

When the first observation was carried out, I couldn't detect any action or conversation in which sex or gender was significant. However, the preschool teachers told me that they just started to work with gender but had not quite come into it yet. I experienced the opposite. The teachers speak to girls and boys equally and think it's the personalities that govern children's play and their behaviours, not their sex. Once a teacher said, "Gender is to let children be who they are, without influence from us, adults. We shall not force boys to play with dolls and girls to play with cars. However, we shall help and support children daring to be who they are, whatever they like to do."

During my observation, it emerged that the children at the preschool are in an activity well-adapted to the new curriculum (Lpfö98, revised 2010). In free play, the kids are for the most part divided into groups where girls and boys are separated. By looking at their clothes and playing activities, a child's sex is obvious since most of them follow typical gender patterns: girls wear pink and boys wear blue, girls are calm and boys ravage around. ... Although most of the children show distinct gender roles and play in specific groups, they demonstrate an acceptance for someone not being like all the others. The new revised curriculum (Lpfö 98, revised 2010) states that preschool should work for all children to be secure in their own identities. (Lotta)

Lotta chose to illustrate her view about gender by quoting a preschool teacher. The teacher argued that if we (the adults) do not interfere with the children, then they will develop their own identities and pure interests. Moreover, the children have innate core identities that the preschool teachers should support so the children can dare "to be who they are," whatever that might be. The idea of an essential core identity can be traced back to Rousseau (1762), as well as the idea that human natural being can be corrupted with the burden of culture.

Lotta declared that she could not see any situations where gender mattered, but at the same time, clear observational differences between girls and boys are described. In her analysis, Lotta distinguished girls and boys as two discrete groups. She separated girls and boys on a structural level, where playing with dolls or cars, colour and types of clothes and traits like calm and rowdy constitute symbols for these groups, according to Harding's symbolic level (1986). According to Harding (1986), symbols can be culturally conditioned representations. 
They must be learned through the prevailing discourse in order to be understood, such as the assumption that pink is a girl's colour and blue is a boy's colour. The colours constitute symbols, in this case for the different sexes, though they do not hold any real relationship to each other. By using symbols such as clothing or toys, the affiliation of the user is shown without any explanation (Harding 1986). It also works the other way around: by using the symbols attributed to individuals' properties, irrefutable types are created. The symbols are sufficient to establish a widely recognized and accepted grouping.

The separation of girls and boys is so taken for granted that Lotta could not recognize it: she even stated she could not detect that sex or gender was significant. The view Lotta expressed means an acceptance of typifying, where the variation within a group is made invisible (Hellman 2010), and she does not question this gender pattern. The consequence of this reasoning is that stereotypical gender patterns will not be counteracted, though this goal is clearly stated in the Swedish curriculum. Instead, these patterns become established as the obvious norm. In the quote above, Lotta used both the preschool teacher's statement and the curriculum to support her position that gender issues are about letting children be who they are. The actual formulation in the curriculum (Lpfö98, revised 2010) can indeed be interpreted as each child having a true identity and that it is the preschool teacher's responsibility to support the child in developing their identity. Lotta's interpretation of the intentions of the curriculum focuses on the importance for children to have an influence on the activities, leading to a strong individual-centred approach. This understanding makes it difficult to generalize different events into symbolic and structural patterns. Through the rhetoric of letting children be who they are, the children are left alone and the preschool teachers do not take on the responsibility of challenging and directing the children and their activities. If preschool teachers like Lotta lack the ability to recognize and understand influences on symbolic and structural levels, the children, instead of being challenged and introduced to a variety of activities, become typified in classic gender patterns.

\section{Discourse Ambivalent}

As mention above, the discourse Ambivalent appears in the written assignments from three students and consists of statements that are categorized as Essentia and Construare within the same text. It is typical among these three students that they vacillate between the two different views of children. Another commonality is that they pose a lot of questions instead of arguments. An example of this can be seen in a quote from Alex's text:

During my preschool placement, I heard a three-year-old boy say "When I become a girl, I will have plaits". /.../ My interpretation is that this boy believes he will become a girl when he gets older. My question is then, how should I have responded? Should I have explained to him how the reality is, that he will not become a girl when he gets older or should I just let it be? (Alex)

Alex is confused and cannot figure out how to approach the situation. Our interpretation is that this confusion is about whether Alex should tell the boy the truth that he will not become a girl or leave it so she does not have to contradict him. It seems to be important for Alex that the boy should be able to separate the sexes in a stable manner, and she feels that she should correct him. However, Alex also wants to support the boy's own assumption. Alex's focus on this dilemma hinders her from thinking about the described situation in a broader perspective. For example, Alex 
could have challenged the boy's view that only girls could have plaits. In another observation, Alex continues to ponder the gender differences:

Why does separate "girls' and boys' play" exist? On one afternoon, I observed the children playing in the yard. The boys are jostling and competing to jump as far as possible. The girls are playing with dolls and doll prams on the hill and some girls are on swings. Some boys are playing with cars in the sandpit. In these situations, it was so obvious how boys and girls formed separate groups and played different kinds of plays. But is this genetically inherent or is it learned behaviour? When I noticed this, I discussed the question with the preschool teachers. (Alex)

Alex's ambivalent approach is shown by the questions she poses about whether children's gender-stereotypical play is innate or dependent on nurture and environment. It seems to be important for Alex to make up her mind about whether the girls' and boys' respective plays are mostly inherited or learned. As previously shown in the "Background" section, this question is heavily debated both among researchers as well as among people in general.

\section{Discussion}

The two dominant discourse models of children discussed in this paper, Essentia and Construare, can be looked upon as different theoretical frameworks for understanding children and explaining their actions. Pre-service teachers who make use of one or the other of these theories may do so unconsciously: that is, their theoretical frameworks are implicit. However, whichever framework they use, it will in different ways affect children in preschool, resulting in openings or closures of possibilities.

\section{The Perception of Children and the Pedagogy of Science}

A conclusion that can be drawn from the results in the present study is that pre- and in-service teachers' views of children, their gender awareness and their pedagogies of science are intimately interwoven. Discourse Essentia consists of presumptions that children's attributes, which are seen as biologically predestined, should be developed so that the children can be the individuals they are meant to be. The idea that a young child has a stable core that is her or his innate identity originates from the assumption that the influence of heredity is socially and culturally superior in the individual. This affects the role preschool teachers will take on. Their tasks will be to follow the child and look for the child's own intentions. Hence, preschool teachers do not have leading operational roles, since they do not see it as their job to influence the child and her or his interests. In the discourse Essentia, the views of the children seem to fit into innate explanations of gender. The differences between girls and boys are seen as natural and thereby should neither be affected nor challenged. A consequence is that preschool teachers do not need to question their own presumptions or struggle to change their views. For the pedagogy of science, this means that girls and boys can be directed towards different subject areas, which in the future can lead to gender-related choices in education and occupations - even though the individuals think they make free choices according to interests. Thus, the reasoning within discourse Essentia also leads to a dead end for equity work. Feminist scholars (Butler 1990; Harding 1986; Hirdman 1990) have argued that presumptions about gender in society are affected by how gender has been constituted culturally and 
historically. According to, for example, Haraway (1991), Hirdman (1990) and Keller and Longino (1996), ideas about subjects (like science) and what kinds of abilities are needed for the subject are also governed by socio-cultural factors. Instead of working for equity and counteracting stereotypical behaviours, the pre-service teachers start out from their own understandings of science and gender and make interpretations of the children's inherent interests.

A complicating factor that has emerged from the analysis of the empirical material is that the Swedish national curriculum has policies that easily can be interpreted in contradictory ways (Lpfö 98, revised 2010). On one hand, the objectives state the teachers' responsibility to counteract stereotypical gender patterns, but on the other hand, the curriculum demands that teachers strive to ensure that each child develops her or his own identity, two directives which can be difficult for preschool teachers to balance. This paradox is important to address, especially since the individual-centred wording in the curriculum has had a strong impact on teacher education (Brembeck et al. 2004). Discourse Construare opens up for a more diverse view of children, irrespective of gender. Here, the pre-service teachers see that they have an important role in facilitating and presenting new topics for the children. Within this discourse, the pre-service teachers reason that the teachers have a responsibility to encourage children to broaden their interests and to challenge children to engage in activities that are not determined by traditional gender stereotypic viewpoints. A hypothetical prediction is that children that have been in classrooms with Construare preschool teachers will more easily make nontraditional gender choices considering activities and former educational choices. In the long term, this gender-aware pedagogy may equalize gender bias within the strongly gendersegregated labour market.

\section{A Process for Gender-Aware Teaching}

From the empirical material and the results, we have designed a model that illustrates a process for gender-aware teaching. The model is applicable to pre- and in-service teachers' pedagogical practises. The process is illustrated in Fig. 2, where the triangle points represent necessary actions for a direction towards more gender-aware teaching. These actions are detect, counteract, and self-reflect. To detect gendered situations was a starting point for the process and an increased awareness. Then, the detection in itself opened up self-reflection and/or the possibility to counteract stereotypical gender patterns. An entrance into the spiralled gender-awareteaching model can be the discourse Ambivalent, where the traditional tacit gender norms are beginning to be questioned. Once a teacher has started to pay attention to gendered situations, the likelihood for continuing to do so increases, as well as for being able to counteract and selfreflect. In fact, this process can be regarded as almost irreversible.

Different parts of the model can be illustrated by our empirical examples. In the dinosaurs/ friendship group situation, Anna described how she observed preschool teachers excluding girls from engaging in science; she detected a potential problematic episode where girls could be the losers. Anna acted in this situation by questioning the teachers' planning and thereby trying to counteract a stereotypical gender pattern. In Stina's case, she detected a mother counteracting stereotypical behaviour, which in turn led to self-reflection where Stina became aware of her own prejudice about girls' and boys' play preferences. Self-reflection may influence the way teachers work against stereotypical gender patterns: by noticing their own actions and thoughts, teachers thereby may change the behaviours. But, the opposite can also be true: counteracting stereotypical gender patterns may entail self-reflection. To critically 
Fig. 2 Model illustrating a process for increased gender awareness in teaching

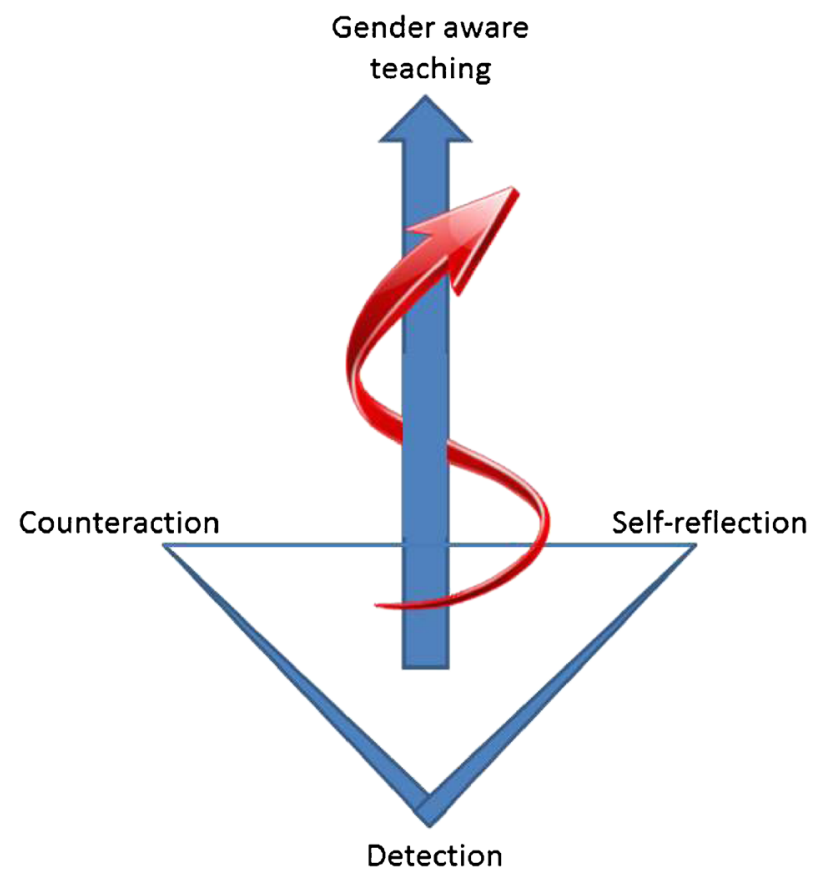

scrutinize one's own and others' actions might show ways to detect new stereotypical situations within the practice of teaching. Thereby, the process is driven towards increasingly gender-aware teaching. Once entering this spiral, the teacher gains a broader repertoire for handling subject-specific situations in a gender-sensitive manner. This will ensure that teachers evaluate and make use of children's unprecedented knowledge about science phenomena in accordance with Siry's (2013) definition of emerging science in preschool. However, knowledge about gender and a gender theoretical framework is crucial for starting the process, and this knowledge interacts constantly with the three aspects in the triangle points of the model.

The quotes from the pre-service teachers used in this study represent typical situations that appear in the students' assignments. At first glance, the situations may seem to be rather innocent and not conspicuous, but they are actually deceptive since these kinds of situations often pass unnoticed. They are repeated over and over and thereby shape parents', preschool teachers' and most importantly the children's own ideas about possible interests and activities. These small occasions are internalized by the child and influence their identity formation. These reoccurring influences will be so integrated that the choices a person makes will be apprehended as innate, even later in life according to educational and professional norms.

\section{Conclusions}

In summary, our results show that gender-unaware pedagogy, like discourse Essentia, has consequences at a subject level, and teachers' preconceptions about the children and the subject in fact may limit children's opportunities and interests. On the other hand, gender-aware pedagogy that consciously counteracts stereotypical gender structures provides children with 
more opportunities to develop a variety of subject interests, as seen in pre-service teachers' reflections in line with the discourse Construare model. With this discourse as a springboard, we have developed a gender-aware teaching model. This model illustrates a process whereby teachers develop a repertoire of teaching strategies, which is a crucial part of their pedagogy of science. Our conclusion is that raising gender issues on a general level in an effort for a more equal society is important but not sufficient. For future choices of education and profession to be less gender biased, gender awareness is needed at a subject-specific level. If stereotypical ideas are challenged and changed, there is a potential to develop science education that broadly engages all children. As a consequence, science itself as a subject may develop.

Acknowledgements This project has been financially supported by the Swedish Research Council. Also, thanks are given to Klara Hussénius for the design of the figure and Rebecca Ahlfeldt for the linguistic correction of the manuscript.

\section{Appendix}

School placement assignment for pre-service teachers:

\section{Recognize situations or conversations where gender matters.}

Observe interactions between children, child-teacher, child(ren)-materials/toys and/or between adults (if you do your internship at a preschool).

II. 'Capture'; the scientific culture

Try to get access to the story told together with the knowledge matter conveyed. By that, we mean what is explicitly and implicitly told about science. What is valued as important knowledge and what seems to be important for students to learn? How shall one be to be a successful student/pupil in science? Note how the science subjects are presented. How do people talk about these topics, how do they work with them, who speaks (the teacher, some students, all but in different contexts), etc.?

Use a journal and write down your observations, preferably in connection with your observation. Either make notes in the journal directly or make use of an audio recorder and record a short description of the observation. At the end of the day, you can transfer your observations into the journal by listening and writing them down. In a descriptive way, try to write down the observed situations with as much detail as possible. This will be the data that you later (see Task III below) will try to interpret and analyse.

\section{Written assignment}

After the school-placement period, we will have a seminar about your experiences. In preparation for the seminar, you should compile your results from tasks 1 and 2 in an essay. Your essay should be four to five pages, single-spaced, and written in 12-point Times New Roman font.

1. Write an initial brief background: description of the school, the class, the teacher's orientation/specialization, as well as a short description of the teaching undertaken during your stay, etc. 
2. Then, describe in detail (for others to be able understand your later analysis) some of the cases/situations from task 1 .

3. Follow up with your own reflections and analysis. Please refer to relevant literature (such as gender theories) in the reflection section.

4. Then, describe in detail some of the sessions from task 2 .

5. Write an analysis (see paragraph 3 above).

6. In a final discussion, try to tie up your conclusions. For example, are there similarities, points of contact between assignments I and II?

Open Access This article is distributed under the terms of the Creative Commons Attribution 4.0 International License (http://creativecommons.org/licenses/by/4.0/), which permits unrestricted use, distribution, and reproduction in any medium, provided you give appropriate credit to the original author(s) and the source, provide a link to the Creative Commons license, and indicate if changes were made.

\section{References}

Appleton, K. (2005). Science pedagogical content knowledge and elementary school teachers. In K. Appleton (Ed.), Elementary science teacher education: international perspectives on contemporary issues and practice (pp. 31-54). Mahwah: L. Erlbaum Associates.

Andersson, K. (2012). "It's funny that we don't see the similarities when that's what we're aiming for" Visualizing and challenging teachers' stereotypes of gender and science. Research in Science Education, 42(2), 281-302.

Andersson, K., \& Gullberg, A. (2014). What is science in preschool and what do teachers have to know to empower children? Cultural Studies of Science Education, 9(2), 275-296. doi:10.1007/s11422-012-9439-6.

Andersson, K., Hussénius, A., \& Gustafsson, C. (2009). Gender theory as a tool for analysing science teaching. Teaching and Teacher Education, 25, 336-343. doi:10.1016/j.tate.2008.09.011.

Beilock, S. L., Gunderson, E. A., Ramirez, G., \& Levine, S. C. (2010). Female teachers' math anxiety impacts girls' math achievement. Proceedings of the National Academy of Sciences, 107(5), 1860-1863.

Braun, V., \& Clarke, V. (2006). Using thematic analysis in psychology. Qualitative Research in Psychology, 3 , $77-101$.

Brembeck, H., Johansson, B., \& Kampmann, J. (2004). Beyond the competent child: exploring contemporary childhoods in the Nordic welfare societies (1st ed.). Frederiksberg: Roskilde University Press.

Butler, J. (1990). Gender trouble. Feminism and the subversion of identity. London: Routledge.

Ceci, S. J., Williams, W. M., \& Barnett, S. M. (2009). Women's underrepresentation in science: sociocultural and biological considerations. Psychological Bulletin, 135(2), 218-261.

Claxton, G., \& Meadows, S. (2009). Brightening up: how children learn to be gifted. In T. Balchin, B. Hymer, \& D. J. Matthews (Eds.), The Routledge international companion to gifted education (pp. 3-9). London: Routledge.

Corsaro, W. (2005). The sociology of childhood. Thousand Oaks: Pine Forge Press.

Dahlberg, G., Moss, P., \& Pence, A. (2002). Från kvalitet till meningsskapande: Postmoderna perspektivexemplet förskolan [From quality to meaning making: postmodern perspectives - the case of preschool]. Stockholm: HLS förl.

Edström, C. (2009). Pre-school as an arena of gender policies: the examples of Sweden and Scotland. European Educational Research Journal, 8(4), 534-549.

Eshach, H. (2006). Science literacy in primary schools and pre-schools. Dordrecht: Springer.

Gee, J. P. (2005). An introduction to discourse analysis: theory and method. New York: Routledge.

Halldén, G. (2007). Den moderna barndomen och barns vardagsliv [Modern childhood and children's everyday lives]. Stockholm: Carlsson.

Haraway, D. (1991). Simians, cyborgs and women: the reinvention of nature. New York: Routledge.

Harding, S. (1986). The science question in feminism. Ithaca: Cornell University Press.

Hausmann, R., Schab, K., Brende, B., Zahidi, S., Bekhouche, Y., Guinault, A., Soo, A., \& Tyson, L. D. (2013). The global gender gap report 2013. Geneva, Switzerland: World Economic Forum.

Hellman, A. (2010). Kan Batman vara rosa? Förhandlingar om pojkighet och normalitet på en förskola [Can Batman be pink? Negotiations about boyishness and normativity in a preschool]. Diss. Göteborg: Göteborgs universitet, 2010. Göteborg. 
Hirdman, Y. (1990). Genussystemet. In SOU 1990:44, Demokrati och makt i Sverige. [Swedish Government Official Report, SOU 1990:44 Democracy and Power in Sweden] Stockholm.

Huang, S. L., \& Fraser, B. J. (2009). Science teachers' perceptions of the school environment: gender differences. Journal of Research in Science Teaching, 46(4), 404-420.

Hundeide, K. (2006). Sociokulturella ramar för barns utveckling: barns livsvärldar [Sociocultural conditions for children's development: children's lifeworlds]. Lund: Studentlitteratur.

Hussénius, A., Andersson, K., Gullberg, A., \& Scantlebury, K. (2013). Ignoring half the sky: a feminist perspective on the missing standpoints in science education research. In N. Mansour \& R. Wegerif (Eds.) Science Education for Diversity in Knowledge Society (pp. 301-316). Rotterdam: Springer Publishing. doi:10.1007/978-94-007-4563-6_14.

Hussénius, A., Andersson, K., Daniēsson, A. \& Gullberg, A. (2014). Ämnesinnehåll och genusmedvetenhet i samspel för en mer inkluderande naturvetenskap (Subject content and gender awareness in interaction for a more inclusive science). Högre utbildning, 4(2), 109-125.

Hussénius, A., Andersson, K. \& Gullberg, A. (2015). Spotting the science culture - Integrating gender perspectives into science courses. International Journal of Gender, Science and Technology, 7(1), 91-103.

Hyde, J. S., \& Mertz, J. E. (2009). Gender, culture, and mathematics performance. PNAS, 106(22), 8801-8807.

James, A., Jenks, C., \& Prout, A. (1998). Theorizing childhood. Cambridge: Polity Press.

Johansson, E. (2011). Investigating morality in toddler's life-worlds. In E. Johansson \& E. J. White (Eds.), Educational research with our youngest: voices of infants and toddlers (pp. 39-62). Dordrecht: Springer Science + Business Media B.V.

Kahle, J. B., \& Meece, J. L. (1994). Research on gender issues in the classroom. In D. Gabel (Ed.), Handbook of research in science teaching (pp. 415-437). New York: MacMillian Publishing Company.

Kahle, J. B., Anderson, A., \& Damnjanovic, A. (1991). A comparison of elementary teacher attitudes and skills in teaching science in Australia and the United States. Research in Science Education, 21, 208-216.

Keller, E. F., \& Longino, H. E. (1996). Feminism and science. Oxford: Oxford Univ. Press.

Lindberg, S. M., Hyde, J. S., Petersen, J. L., \& Linn, M. C. (2010). New trends in gender and mathematics performance: a meta-analysis. Psychological Bulletin, 136, 1123-1135.

Lpfö98, Läroplan för förskolan, reviderad. (2010). [National curriculum for the preschool, revised 2010]. Skolverket: The Swedish National Agency for Education.

Moss-Racusin, C. A., Dovidio, J. F., Brescoll, V. L., Graham, M. J., \& Handelsman, J. (2012). Science faculty's subtle gender biases favor male students. Proceedings of the National Academy of Sciences, 109(41), 16474-16479.

Rousseau, J. (1762). Émile, ou, De l'éducation (Emile or Treatise on education). Francfort: [s.n.].

Rubin, G. (1975). The traffic in women: notes on the "political economy" of sex. In R. Reiter (Ed.), Toward an anthropology of women (pp. 157-210). New York: Monthly Review Press.

Scantlebury, K. (2014). Gender matters: building on the past, recognizing the present, and looking towards the future. In S. K. Abell, \& N. Lederman, (Eds.), Handbook of Research on Science Education, Volume 2 (pp. 187-203). New York: Routledge.

She, H. C., \& Fisher, D. (2002). Teacher communication behaviour and its association with students' cognitive and attitudinal outcomes in science in Taiwan. Journal of Research in Science Teaching, 39(1), 63-78.

Shields, S. (1975). Functionalism, Darwinism, and the psychology of women. American Psychologist, 30, 739754.

Shulman, L. S. (1986). Those who understand: knowledge growth in teaching. Educational Researcher, 15(2), 4 14.

Sikder, S., \& Fleer, M. (2015). Small science: infants and toddlers experiencing science in everyday family life. Research in Science Education, 45(3), 445-464.

Siraj-Blatchford, J. (2001). Emergent science and technology in the early years. Paper presented at the XXIII World Congress of OMEP. Santiago Chile July 31 to 4 August 2001.

Siry, C. (2013). Exploring the complexities of children's inquiries in science: knowledge production through participatory practices. Research in Science Education, 43(6), 2407-2430. doi:10.1007/s11165-013-9364-z.

Siry, C. (2014). Towards multidimensional approaches to early childhood science education. Cultural Studies of Science Education, 9(2), 297-304.

Sjøberg, S. (2000). Naturvetenskap som allmänbildning—en kritisk ämnesdidaktik. [Natural science as general education - a critical pedagogical knowledge]. Lund: Studentlitteratur.

Spelke, E. S. (2005). Sex differences in intrinsic aptitude for mathematics and science? American Psychologist, $60(9), 950-958$.

Spencer, S. J., Steele, C. M., \& Quinn, D. M. (1999). Stereotype threat and women's math performance. Journal of Experimental Social Psychology, 35, 4-28.

Stoet, G., \& Geary, D. C. (2012). Can stereotype threat explain the gender gap in mathematics performance and achievement? Review of General Psychology, 16(1), 93-102. 
Sverige Statistiska centralbyrån, enheten för befolkningsstatistik (eds.) (2012). På tal om kvinnor och män: lathund om jämställdhet. 2012. [Speaking about women and men: a manual about equity. 2012].Stockholm: Statistiska centralbyrån.

Swedish School Inspectorate Skolinspektionens rapport 2012:7 Stockholm 2012.

Thulin, S. (2011). Lärares tal och barns nyfikenhet: kommunikation om naturvetenskapliga innehåll i förskolan. [Teacher talk and children's queries: communication about natural science in early childhood education]. Diss. (sammanfattning) Göteborg: Göteborgs universitet, 2011. Göteborg.

Weiner, G., \& Berge, B. (2001) Kön och kunskap [Gender and knowledge]. Lund: Studentlitteratur. 